\title{
The role of noninvasive ventilation in acute cardiogenic pulmonary edema
}

\author{
Ashar Salman, Eric B Milbrandt² and Michael R Pinsky ${ }^{3}$ \\ University of Pittsburgh Department of Critical Care Medicine: Evidence-Based Medicine Journal Club, edited by Eric B Milbrandt
}

\begin{abstract}
Expanded Abstract
Citation

Gray A, Goodacre S, Newby DE, Masson M, Sampson F, Nicholl J: Noninvasive ventilation in acute cardiogenic pulmonary edema. N Engl J Med 2008, 359:142-151 [1].
\end{abstract}

\section{Background}

Noninvasive ventilation (NIV) (continuous positive airway pressure [CPAP] or noninvasive intermittent positivepressure ventilation [NIPPV]) appears to be of benefit in the immediate treatment of patients with acute cardiogenic pulmonary edema and may reduce mortality.

\section{Methods}

Objective: To determine whether noninvasive ventilation reduces mortality and whether there are important differences in outcome associated with the method of treatment (CPAP or NIPPV).

Design: Open, prospective, randomized controlled trial.

Setting: 26 emergency departments in hospital in the UK between July 2003 and April 2007.

Subjects: 1069 patients age >16 years with a clinical diagnosis of acute cardiogenic pulmonary edema, as determined by chest radiograph, respiratory rate $>20$ breaths/min, and arterial $\mathrm{pH}<7.35$. Exclusion criteria included a requirement for a lifesaving or emergency intervention, inability to give consent, or previous recruitment in the trial.

Intervention: All patients received standard concomitant therapy. Patients were randomly assigned to standard oxygen therapy (up to 15 liters per minute via face mask), CPAP (5 to $15 \mathrm{~cm}$ of water), or NIPPV (inspiratory pressure, 8 to $20 \mathrm{~cm}$ of water; expiratory pressure, 4 to $10 \mathrm{~cm}$ of water).

Outcomes: The primary end point for the comparison between noninvasive ventilation and standard oxygen therapy was death within 7 days after the initiation of treatment, and the primary end point for the comparison between NIPPV and CPAP was death or intubation within 7 days.

\section{Results}

A total of 1069 patients (mean [ \pm SD] age, $77.7 \pm 9.7$ years; female sex, 56.9\%) were assigned to standard oxygen therapy (367 patients), CPAP (346 patients), or NIPPV (356 patients). There was no significant difference in 7-day mortality between patients receiving standard oxygen therapy (9.8\%) and those undergoing noninvasive ventilation $(9.5 \%, P=0.87)$. There was no significant difference in the combined end point of death or intubation within 7 days between the two groups of patients undergoing noninvasive ventilation (11.7\% for CPAP and $11.1 \%$ for NIPPV, $\mathrm{P}=0.81$ ). As compared with standard oxygen therapy, noninvasive ventilation was associated with greater mean improvements at 1 hour after the beginning of treatment in patient-reported dyspnea (treatment difference, 0.7 on a visual-analogue scale ranging from 1 to $10 ; 95 \%$ confidence interval $[\mathrm{Cl}], 0.2$ to $1.3 ; \mathrm{P}=0.008$ ), heart rate (treatment difference, 4 beats per minute; $95 \% \mathrm{Cl}, 1$ to $6 ; \mathrm{P}=0.004$ ), acidosis (treatment difference, $\mathrm{pH} 0.03 ; 95 \% \mathrm{Cl}, 0.02$ to 0.04 ; $\mathrm{P}<0.001$ ), and hypercapnia (treatment difference, $0.7 \mathrm{kPa}[5.2 \mathrm{~mm} \mathrm{Hg}] ; 95 \% \mathrm{Cl}, 0.4$ to $0.9 ; \mathrm{P}<0.001$ ). There were no treatment-related adverse events.

\section{Conclusion}

In patients with acute cardiogenic pulmonary edema, noninvasive ventilation induces a more rapid improvement in respiratory distress and metabolic disturbance than does standard oxygen therapy but has no effect on short-term mortality.

\section{Biomed Central}

2010 BioMed Central Ltd
*Correspondence: milbeb@UPMC.EDU

${ }^{2}$ Assistant Professor, Department of Critical Care Medicine, University of Pittsburgh School of Medicine, Pittsburgh, Pennsylvania, USA

Full list of author information is available at the end of the article 


\section{Commentary}

Acute cardiogenic pulmonary edema (ACPE) is common, costly, and lethal, with associated mortality rates of 10$20 \%[2,3]$. When severe, it is traditionally managed with endotracheal intubation and mechanical ventilation. Interest in using noninvasive ventilation (NIV) in the treatment of ACPE has grown since the early work of Rasanen and colleagues from 1985 [4]. Whether delivered in the form of continuous positive airway pressure (CPAP) or noninvasive intermittent positive pressure ventilation (NIPPV), NIV improves physiologic parameters in patients with ACPE, including decreasing respiratory acidosis, respiratory rate, work of breathing, heart rate, and sensation of dyspnea [5,6]. It may also reduce rates of endotracheal intubation [5,7,8]. A variety of clinical trials have been conducted in this area, though most were small, single-centered studies lacking power to determine if NIV reduces mortality [4,9-18]. Recent systematic reviews and meta-analyses suggest that indeed it may [5-8]. However, the small size of included studies and variation in study populations, interventions, and endpoints leave some doubt to the generalizability of these findings.

To address these uncertainties, Gray and colleagues performed a large, multi-center, randomized controlled trial in 1069 patients with ACPE to determine whether NIV improves survival and if NIPPV is superior to CPAP [1]. Their trial, referred to as the $3 \mathrm{CPO}$ (Three interventions in Cardiogenic Pulmonary Oedema) study, was completed in 26 emergency departments in the UK. Patients were randomized to three groups: standard oxygen therapy, CPAP $\left(5-15 \mathrm{~cm}\right.$ of $\left.\mathrm{H}_{2} \mathrm{O}\right)$, or NIPPV (8/4 to $20 / 10 \mathrm{~cm}$ of $\mathrm{H}_{2} \mathrm{O}$ ). There were no differences in baseline characteristics, comorbid conditions, or the receipt of standard medical treatments, such as diuretics, nitrates and opiates. Though NIV did provide more rapid improvement in respiratory distress and metabolic disturbances, there were no differences in clinical outcomes, including mortality, rates of endotracheal intubation, length of stay, or myocardial infarction. There were no differences between CPAP and NIPPV in any of the primary or secondary outcomes. The authors conclude that in patients with ACPE, noninvasive ventilation produces more rapid resolution of metabolic abnormalities and respiratory distress but has no effect on short-term mortality.

This study has a number of strengths, most important of which is that it was the largest randomized trial to date in this area, enrolling more patients than the combined number of patients from all studies included in prior meta-analyses [5-8]. Some limitations deserve mention. This was a study of patients presenting to the emergency department and therefore may not apply to the use of NIV in the pre-hospital setting or to those patients who develop ACPE later in their hospital stay. Patients were excluded if they required lifesaving or emergency intervention, a group that might have benefited most from NIV. The most concerning limitation, however, is the considerable cross-over between groups and the lack of objective criteria for intubation. Fifty-six patients who failed standard oxygen treatment were rescued with NIV. Assuming that all 56 would have required intubation, the control 7-day intubation rate would have increased from $2.8 \%$ to $18.0 \%$, which would have made the intubation rate in the standard oxygen treatment group significantly greater than the NIV group (2.9\%).

\section{Recommendation}

The results of this study should not limit the use of NIV in the setting of ACPE. NIV leads to more rapid improvement of symptoms of respiratory distress and metabolic disturbances as compared to standard oxygen therapy. We further argue that based on this study, one should not draw a conclusion that NIV is ineffective in preventing intubation. Though NIV has not been convincingly shown to reduce mortality, it remains a valuable adjunct in the treatment of ACPE.

\section{Author details}

'Clinical Fellow, Department of Critical Care Medicine, University of Pittsburgh School of Medicine, Pittsburgh, Pennsylvania, USA

${ }^{2}$ Assistant Professor, Department of Critical Care Medicine, University of Pittsburgh School of Medicine, Pittsburgh, Pennsylvania, USA

${ }^{3}$ Professor, Department of Critical Care Medicine, University of Pittsburgh School of Medicine, Pittsburgh, Pennsylvania, USA

\section{Competing interests}

The authors declare that they have no competing interests.

Published: 12 March 2010

\section{References}

1. Gray A, Goodacre S, Newby DE, Masson M, Sampson F, Nicholl J: Noninvasive ventilation in acute cardiogenic pulmonary edema. N Engl J Med 2008, 359:142-151.

2. Jessup M, Brozena S: Heart failure. N Engl J Med 2003, 348:2007-2018.

3. Nieminen MS, Brutsaert D, Dickstein K, Drexler H, Follath F, Harjola VP, Hochadel M, Komajda M, Lassus J, Lopez-Sendon JL, Ponikowski P, Tavazzi L: EuroHeart Failure Survey II (EHFS II): a survey on hospitalized acute heart failure patients: description of population. Eur Heart J 2006, 27:2725-2736.

4. Rasanen J, Heikkila J, Downs J, Nikki P, Vaisanen I, Viitanen A: Continuous positive airway pressure by face mask in acute cardiogenic pulmonary edema. Am J Cardiol 1985, 55:296-300.

5. Masip J, Roque M, Sanchez B, Fernandez R, Subirana M, Exposito JA: Noninvasive ventilation in acute cardiogenic pulmonary edema: systematic review and meta-analysis. JAMA 2005, 294:3124-3130.

6. Vital FM, Saconato H, Ladeira MT, Sen A, Hawkes CA, Soares B, Burns KE, Atallah AN: Non-invasive positive pressure ventilation (CPAP or bilevel NPPV) for cardiogenic pulmonary edema. Cochrane Database Syst Rev 2008, CD005351.

7. Peter JV, Moran JL, Phillips-Hughes J, Graham P, Bersten AD: Effect of noninvasive positive pressure ventilation (NIPPV) on mortality in patients with acute cardiogenic pulmonary oedema: a meta-analysis. Lancet 2006, 367:1155-1163.

8. Winck JC, Azevedo LF, Costa-Pereira A, Antonelli M, Wyatt JC: Efficacy and safety of non-invasive ventilation in the treatment of acute cardiogenic pulmonary edema--a systematic review and meta-analysis. Crit Care 2006, 10:R69. 
9. Bersten AD, Holt AW, Vedig AE, Skowronski GA, Baggoley CJ: Treatment of severe cardiogenic pulmonary edema with continuous positive airway pressure delivered by face mask. NEngl J Med 1991, 325:1825-1830.

10. Crane SD, Elliott MW, Gilligan P, Richards K, Gray AJ: Randomised controlled comparison of continuous positive airways pressure, bilevel non-invasive ventilation, and standard treatment in emergency department patients with acute cardiogenic pulmonary oedema. Emerg Med J 2004, 21:155-161.

11. Kelly CA, Newby DE, McDonagh TA, Mackay TW, Barr J, Boon NA, Dargie HJ, Douglas NJ: Randomised controlled trial of continuous positive airway pressure and standard oxygen therapy in acute pulmonary oedema; effects on plasma brain natriuretic peptide concentrations. Eur Heart $J$ 2002, 23:1379-1386

12. L'Her E, Duquesne F, Girou E, de Rosiere XD, Le Conte P, Renault S, Allamy JP, Boles JM: Noninvasive continuous positive airway pressure in elderly cardiogenic pulmonary edema patients. Intensive Care Med 2004, 30:882-888

13. Lin M, Yang YF, Chiang HT, Chang MS, Chiang BN, Cheitlin MD: Reappraisal of continuous positive airway pressure therapy in acute cardiogenic pulmonary edema. Short-term results and long-term follow-up. Chest 1995, 107:1379-1386.

14. Masip J, Betbese AJ, Paez J, Vecilla F, Canizares R, Padro J, Paz MA, de Otero J, Ballus J: Non-invasive pressure support ventilation versus conventional oxygen therapy in acute cardiogenic pulmonary oedema: a randomised trial. Lancet 2000, 356:2126-2132.
15. Nava S, Carbone G, DiBattista N, Bellone A, Baiardi P, Cosentini R, Marenco M, Giostra F, Borasi G, Groff P: Noninvasive ventilation in cardiogenic pulmonary edema: a multicenter randomized trial. Am J Respir Crit Care Med 2003, 168:1432-1437

16. Park M, Lorenzi-Filho G, Feltrim MI, Viecili PR, Sangean MC, Volpe M, Leite PF, Mansur AJ: Oxygen therapy, continuous positive airway pressure, or noninvasive bilevel positive pressure ventilation in the treatment of acute cardiogenic pulmonary edema. Arq Bras Cardiol 2001, 76:221-230.

17. Park M, Sangean MC, Volpe MS, Feltrim MI, Nozawa E, Leite PF, Passos Amato MB, Lorenzi-Filho G: Randomized, prospective trial of oxygen, continuous positive airway pressure, and bilevel positive airway pressure by face mask in acute cardiogenic pulmonary edema. Crit Care Med 2004, 32:2407-2415

18. Takeda S, Nejima J, Takano T, Nakanishi K, Takayama M, Sakamoto A, Ogawa R Effect of nasal continuous positive airway pressure on pulmonary edema complicating acute myocardial infarction. Jpn Circ J 1998, 62:553-558.

doi:10.1186/cc8889

Cite this article as: Salman A, et al:: The role of noninvasive ventilation in acute cardiogenic pulmonary edema. Critical Care 2010, 14:303. 